\title{
LEBENSWELT, FILOSOFÍA DEL DERECHO Y CIUDADANÍA COSMOPOLITA EN FACTICIDAD Y VALIDEZ DE HABERMAS ${ }^{1}$
}

IVÁN RAIMUNDO CANALES VALENZUELA

Universidad Autónoma de Chile

\begin{abstract}
RESUMEN: El objetivo de este articulo es exponer los resultados de nuestra revisión del texto Faktizität und Geltung (1992) de J. Habermas, la cual tenía como propósito visualizar si desde el sistema de los derechos fundamentado desde el principio del discurso se puede concebir sistemáticamente una ciudadanía de carácter cosmopolita, y si la restricción categorial que realiza Hebermas sobre su concepto de acción comunicativa, de ser sólo válido para mundos de la vida (Lebenswelt) socio-evolutivamente postconvencionales, es superada en su comprensión del derecho discursivamente fundamentado como medio de integración social.
\end{abstract}

PALABRAS CLAVE: teoría del discurso, integración social, filosofía del derecho, interculturalidad, facticidad y validez.

\section{Lebenswelt, Philosophy of Law and Cosmopolitan Citizenship in Faktizität und Geltung by Habermas}

ABSTRACT: The goal of this article is to expose the results of our review of the J. Habermas' text Faktizität und Geltung (1992), which main purpose was to visualize whether a citizenship of cosmopolitan character is able to be conceived from the beginning of the speech systematically, and whether the categorical restriction that Hebermans performs on his concept of communicative action of being valid only for post-conventional socio-evolutionarily worlds-of-life (Lebenswelt) is superpassed in its understanding of the discursively based rights and laws as a social integration mean.

KEY WORDS: discourse theory, social integration, philosophy of law, intercultural, facticidad and validity.

\section{INTRODUCCIÓN}

En la primera parte de nuestra investigación FONDECYT (cf. nota 1) hemos problematizado la recepción de la categoría fenomenológica de Lebenswelt en la teoría de la acción comunicativa de J. Habermas.

En el contexto del tratamiento sistemático que realiza Habermas del concepto de Lebenswelt, al momento de ofrecer la posibilidad de una articulación teórica entre Lebenswelt y sistema, surge como derivada la categoría forma moderna de entendimiento, la cual es particularmente excluyente de aquellas tradiciones culturales cuyos mundos de la vida exhiben pretensiones de validez provenientes de las

1 FONDECYT de Iniciación 2007/2009, N 11070045. «Génesis, estructura y potencialidad crítica del concepto de Lebenswelt al interior de la heurística negativa de la teoría de la acción comunicativa de Jürgen Habermas». CONICYT-Chile. 
imágenes religiosas rectoras de la praxis. La razón que da Habermas para defender esta exclusión es que «el ámbito de acción sacro se disuelve en buena parte o, a lo menos, deja de tener efectos generadores de estructuras $»^{2}$. Por tanto, los parámetros de visión del radar teórico comunicativo habermasiano no tiene ojos para ver como objeto y como interlocutor válido a las tradiciones religiosas y a las pretensiones de validez que de ellas emergen. Desde esta perspectiva podemos afirmar que la teoría de la acción comunicativa se circunscribe en un horizonte de racionalidad categorial radicalmente secularizado que excluye ex professo la posibilidad de un diálogo social con diferentes tradiciones religiosas en concurrencia ${ }^{3}$. Acto seguido Habermas declara que esta categoría (forma moderna de entendimiento) es la piedra angular de toda su teoría crítica de la modernidad ${ }^{4}$. En el Interludio Segundo (TAC, Vol. II, «Sistema y Mundo de la Vida»), Habermas establece y deja muy claro que la acción comunicativa y la legítima interlocución que presupone, es sólo válida al interior de mundos de la vida socio-evolutivamente postconvencionales, con «acción comunicativa, liberada de aspectos normativos, con institucionalización de la crítica»" ${ }^{5}$ y con "actividad teleológica como acción racional con arreglo a fines éticamente naturalizada (utilización de tecnologías y estrategias de carácter científico) ${ }^{6}$. La exclusión señalada, también queda ratificada en J. Habermas $1981 b$, 278-280. Por tanto, el objetivo de nuestro análisis del texto de Facticidad y Validez (1992), es observar si Habermas, junto con hablar de status de ciudadano del mundo o una cosmo-ciudadanía, levanta también las restricciones categoriales de su teoría de la acción comunicativa, la cual puede liberar todo su potencial racional y comunicativo, sólo en el contextos de mundos de la vida socio-evolutivamente postconvencionales. De no ser así, entonces el discurso habermasiano sobre migración e integración social intercultural, sólo se quedaría en una buena voluntad (commomsense democrático) que tolera amablemente la irracionalidad inherente a los mundos de la vida socio-evolutivamente preconvencionales y convencionales. También es nuestro objetivo subrayar la modificación que realiza Habermas del concepto de patologías del mundo de la vida inducidas sistémicamente, desarrollando la dimensión del derecho, expresamente, como instrumento de mediación y de integración social y no como un inductor más de patologías sistémicas. En síntesis nuestra pregunta es: si una fundamentación de los derechos fundamentales en términos de teoría del discurso; articulando: principio de discurso, forma jurídica y principio democrático; junto con la posibilidad de reformular discursivamente los principios del Estado de derecho y una nueva lógica de la división de poderes; introduciendo el concepto de poder comunicativo, nos abre o no la senda hacia una comprensión sistemática de una ciudadanía cosmopolita donde lo preconvencional, lo convencional y lo postconvencional se integren sistemáticamente en condiciones de libertad y justicia o de legítima interlocusión .

En lo fundamental el texto Facticidad y Validez (1992) es una aportación teórica que reconstruye lógicamente los supuestos de los Estados democráticos de derecho

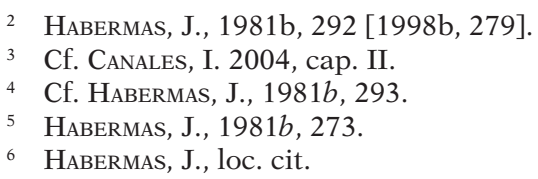


a través del análisis de las constituciones ejemplares del mundo moderno y contemporáneo. Por tanto, se trata de la génesis lógica del sistemas de los derechos o de la reconstrucción conceptual de la identidad articuladora de la realidad del derecho, que funcionaría como instancia crítica para esa propia realidad. Nos encontramos, entonces, ante una perspectiva que reflexiona como filosofía del derecho y como filosofía política y que intenta descubrir y reducir a unidad las relaciones conceptuales y de principio operantes que constituyen la compleja estructura de elementos históricos presentes en la génesis del sistema de los derechos. Los elementos utilizados por Habermas para realizar esta génesis o reconstrucción conceptual son el principio de discurso y la forma jurídica de las normas. Según el primero, «sólo son legítimas aquellas normas de acción que pudieran ser aceptadas por todos los posibles afectados por ellas como participantes en discursos racionales» ${ }^{7}$. Según el segundo, "se trata de normas en las que se prescinde de la capacidad del destinatario de ligar su voluntad por propia iniciativa; que se refieren a asuntos bien tipificados que, por tanto, representan en su materia una violenta abstracción del agente a la hora de atenerse o no a la norma ${ }^{8}$. La forma jurídica queda, entonces, sustraída a la fundamentación racional, porque su introducción está ligada a una explicación funcional, que es propia e inherente al mundo moderno. Se trata, por tanto, de normas de derecho positivo que tienen por objeto la regulación de problemáticas políticas, económicas y sociales. Sin embargo, para Habermas la única posibilidad de fundamentación racional-práctica o la única fuente de normatividad del derecho contemporáneo está en el principio de discurso. Es con la aplicación de este principio que emprende la tarea de realizar una reconstrucción interna del derecho, tematizando primero El sistema de los derechos y posteriormente Los principios del Estado de Derecho. El objetivo de Habermas es poder concluir su análisis con una fundamentación de los derechos fundamentales en términos de teoría del discurso; articulando: principio de discurso, forma jurídica y principio democrático; junto con la posibilidad de reformular discursivamente los principios del Estado de derecho y una nueva lógica de la división de poderes; introduciendo el concepto de poder comunicativo ${ }^{9}$.

Son estos desarrollos los que permitirán a Habermas, más adelante, 1) poder exponer su opción por una democracia, radicalmente deliberativa ${ }^{10}$, a través de la formulación de un concepto procedimental de democracia ${ }^{11}$ y 2) la redefinición del papel de la sociedad civil y de la opinión pública. Es decir, una redefinición de la

7 Habermas, J., 1991b, 68; 1992, 138 [22000, 172].

8 Redondo, J., Introducción a Facticidad y validez de J. Habermas, 22000, 9; cf. Habermas, J., $1981 b, 530-547$ [1998b, 510-527].

9 Cf. Habermas, J., 1992, 151-165; 208-237 [22000, 184-198; 237-262].

10 Habermas ante la desorientación y perdida de seguridad en las sociedades Occidentales articuladas en términos democráticos y de estado de derecho, afirma lo siguiente: «Sospecho, sin embargo, que el malestar y la inquietud tienen una raíz más profunda, a saber, el presentimiento y sospecha de que, bajo el signo de una política completamente secularizada, el Estado de derecho no puede tenerse ni mantenerse sin democracia radical. Convertir este pensamiento en una idea es la tarea de la presente investigación» (HaBermas, J., 1992, 13 [22000, 61].

11 Cf. Habermas, J., 1992, 363ss. [22000, 349ss.]. 
sociedad civil y de sus actores, donde la opinión pública o espacio público quedan definidos como poder comunicativo ${ }^{12}$.

Desde ya podemos advertir, de hecho, una superación de la tesis de la colonización del mundo de la vida entendida como proceso de juridización del mismo. Nos encontramos, por tanto, con una valoración y sistematización discursiva del derecho y del sistema de los derechos que está ausente en el texto Teoría de la acción comunicativa de 1981.

Para realizar nuestro objetivo de precisar qué nuevas puertas categoriales nos abre Habermas, en su filosofía del derecho, para pensar sistemáticamente una integración social de carácter global vamos a exponer en [1] el marco categorial desarrollado en Facticidad y Validez. En [2] vamos a analizar la situación del derecho como categoría de mediación para la integración social. En [3] contrastaremos las categorías jurídico-comunicativas habermasianas con el debate sobre las migraciones. Y en [4] realizaremos un comentario conclusivo sobre la cuestión debatida.

\section{Marco categorial del teXto Facticidad y ValideZ}

En relación con el marco categorial que articula al texto, Habermas lo desarrolla en el primer capítulo, ratificando toda la estructura del núcleo duro de su teoría de la acción comunicativa ${ }^{13}$. Pero esta vez, tratada de forma esquemática y poniendo el acento en la relación o tensión, inmanente al lenguaje, entre facticidad y validez, que afecta a los propios fundamentos de la teoría de la acción comunicativa. Con ello se quiere ratificar que la racionalidad comunicativa no es como la forma clásica de la razón práctica, es decir, una fuente de normas de acción, sino que, más bien «se manifiesta en una trama decentrada [sic] de condiciones trascendentalmente posibilitantes, formadoras de estructuras, y que impregnan la interacción, pero no es una facultad subjetiva que dicte a los actores qué deben hacer» ${ }^{14}$. Por tanto, el carácter normativo de la racionalidad comunicativa queda limitado al hecho de que quien actúa comunicativamente asume de hecho presupuestos pragmáticos de tipo contrafáctico.

"En tal situación, quien actúa comunicativamente se halla bajo ese "tener que" que caracteriza a lo que podemos denominar coerción trascendental del tipo débil (einer schwachen traszendentalen Nötigung), pero no por ello se halla ya ante el "tienes que" prescriptivo de una regla de coacción, se reduzca ese "tienes que" a la validez deontológica de un precepto moral, a la validez axiológica de una constelación de valores objeto de preferencias, o a la eficacia empírica de una regla técnica» ${ }^{15}$.

Para Habermas, esta motivación racional al acuerdo, presente en la racionalidad comunicativa, la cual descansa siempre en un poder-decir-que-no, tiene ciertamente la ventaja de una estabilización no coactiva de expectativas de comportamiento. Y

12 Cf. Habermas, J., 1992, 435-467 [22000, 439-468].

13 Cf. Habermas, J., 1992, 15-60 [²2000, 63-104].

14 Cf. Habermas, J., 1992, 18 [22000, 66].

15 Habermas, J., 1992, 18 [22000, 66]. 
ello asumiendo los altos costes, que tiene para la coordinación de la acción, el riesgo de disentimiento siempre presente. Habermas tiene clara conciencia del problema que representa la interrogante «de cómo de procesos de formación de consenso que vienen amenazados por una tensión explosiva entre facticidad y validez, puede surgir algo así como orden social» ${ }^{16}$. La respuesta de Habermas a esta cuestión, nos vuelve a remitir a una interacción que requiere como condición de posibilidad a un solo universo simbólico compartido o, la interacción comunicativa sólo es posible bajo un solo mundo de la vida y que además haya alcanzado un grado de evolución social que lo sitúe en la categoría de forma moderna del entendimiento. Es decir, que la acción comunicativa debe estar inserta en el contexto del mundo de la vida que le proporcione respaldo mediante un masivo consenso de fondo. Pues el mundo de la vida constituye "el horizonte de las situaciones de habla y a la vez la fuente de operaciones interpretativas ${ }^{17}$. Para Habermas, en el contexto racional comunicativo, el mundo de la vida le interesa sólo como saber de fondo, antepredicativo y precategorial ${ }^{18}$. Que está envuelto en el modo de la certeza inmediata, operando como un saber de fondo que como tal no puede ser falso; pues se descompone tan pronto como, al volverse temático, cae en una espiral de posibilidades de problematización. Se da de este modo, en este saber de fondo, una peculiar neutralización de la tensión entre facticidad y validez. Lo cual le presta una especial estabilidad, inmunizándolo contra la presión de las experiencias generadoras de contingencia ${ }^{19}$.

Habermas precisa que hay también un saber temáticamente disponible ya pasado a través de la acción comunicativa, que cumple una función igualmente estabilizadora de la tensión entre facticidad y validez. Esto sucede en las instituciones de las sociedades tribales, que protegen siempre a través de algún tipo de tabú, las expectativas cognitivas y normativas, que constituyen al complejo de convicciones y de orientaciones valorativas del grupo. Al interior de ese umbral la validez parece coincidir con la fuerza de lo fáctico, quedando sustraídas a la comunicación ya sea en forma de certeza del mundo de la vida como saber de fondo o como restricciones a la comunicación impuestas por una autoridad fascinante. De este modo, el riesgo de disentimiento queda absorbido por la propia dimensión de la validez ${ }^{20}$.

Hasta este lugar, el marco categorial desarrollado por Habermas en teoría de la acción comunicativa permanece, en lo principal, invariable. Efectivamente, como pretende Habermas nos encontramos ante un texto que aplica la teoría de la acción comunicativa a la problemática discursiva que toma la forma de una permanente tensión entre facticidad y validez, tensión que debe ser permanentemente estabilizada comunicativamente a través del derecho. Sin embargo, a continuación Habermas introduce en la teoría de la acción comunicativa una nueva categoría de mediación social que no estaba valorada como tal en los textos de 1981. Recordemos que, si bien es cierto que el mundo de la vida pertenece, estructuralmente,

16 Habermas, J., 1992, 37 [22000, 83].

17 Habermas, J., 1992, 38 [22000, 84].

18 Habermas recuerda que sobre este tópico, ya Husserl había sostenido la importancia de este olvidado fundamento de sentido que representa la práctica comunicativa cotidiana y nuestra experiencia del mundo (cf. Habermas, J., 1992, 38 [22000, 84]; 1991a, 34-90 [1996, 59-73]).

19 Cf. loc. cit.

20 Cf. Habermas, J., 1992, 40 [22000, 85]. 
al ámbito institucional del mundo de la vida, Habermas concibe al derecho como el ámbito a través del cual el sistema coloniza permanentemente al mundo de la vida, juridizándolo. Es esta perspectiva habermasiana sobre el derecho lo que ha cambiado radicalmente en el texto que comentamos (Facticidad y Validez). Observemos ahora detenidamente, este cambio de perspectiva.

\section{EL DERECHO COMO CATEGORÍA DE MEDIACIÓN PARA LA INTEGRACIÓN SOCIAL}

Habermas realiza un tercer paso reconstructivo que nos conduce a la categoría del derecho como categoría de la mediación social. Los desarrollos anteriores nos han explicado cómo es posible la integración social en grupos pequeños y relativamente indiferenciados y con procesos de entendimiento racional mínimos. Pero cuando los espacios para el riesgo y el disentimiento crecen en el curso de la evolución social, y cuanto más aumenta la pluralización de las formas de vida y una individualización de las biografías, aumentan también los espacios de tensión entre facticidad y validez. Pues tanto el saber de fondo que supone el mundo de la vida como la autoridad fascinante, ya no son capaces de solventar las pretensiones de validez de la convicciones y valoraciones compartidas. De este modo, el disentimiento social debe acceder a un nuevo orden de pretensiones de validez ${ }^{21}$. Este nuevo orden supone, para Habermas, una sociedad profundamente profanizada en la que los órdenes normativos han de poder mantenerse sin garantías metasociales. Es decir, una sociedad donde «el peso de la integración social se desplaza cada vez más a las operaciones de entendimiento intersubjetivo de actores para los que quedan irremediablemente separadas validez y facticidad $»^{22}$.

El problema de fondo para Habermas reside en la cuestión de cómo es posible pensar una integración social de mundos de la vida diferenciados y en sí pluralizados y desacralizados, en medio de un creciente riesgo de disentimiento en ámbitos de acción comunicativa, frente a autoridades sacras y liberados de instituciones fuertes. En esta dinámica, queda limitado el potencial de integración que representa el mecanismo del entendimiento, única alternativa razonable de mediación social. El problema de la integración social se agrava también por la liberación de una creciente multitud de interacciones estratégicas que son imprescindibles socioculturalmente en las sociedades modernas. Para Habermas, estamos aquí ante la premisa del continuo disenso en las sociedades modernas, premisa que es fundamental para la articulación de la «teoría de la acción comunicativa ${ }^{23}$. La solución al conflicto o al disenso sólo es posible a través de dos estrategias alternativas para quienes actúan comunicativamente: o se dilate el conflicto no resuelto rompiendo la comunicación o dirimirlo a través de una acción estratégica. Por tanto, para Habermas, lo comunicativamente razonable va a ser "la regulación normativa de interacciones estratégicas en la que, o sobre la que, los propios actores pudieran ponerse

21 Cf. Habermas, J., 1992, 42 [22000, 87].

22 Habermas, J., 1992, 43 [22000, 88].

23 Cf. Habermas, J., 1992, 43 [22000, 88], nota $\mathrm{n}^{\circ} 19$. 
de acuerdo o entenderse ${ }^{24}$. Habermas subraya la paradoja de tales reglas ante las premisas de facticidad y validez. Es decir, que las normas que resulten aptas «para una regulación de las interacciones estratégicas que todos los participantes puedan considerar vinculantes, han de satisfacer dos condiciones contradictorias que desde un punto de vista de los actores no podrían cumplirse simultáneamente» ${ }^{25}$. Por tanto, dichas regulaciones deben, por un lado, representar restricciones fácticas (coerción normativa) y, por otro, esas reglas han de tener a la vez la capacidad de «integrar socialmente», esto es, suponen en la base pretensiones de validez normativas intersubjetivamente reconocidas. De este modo, son los conceptos simultáneos de coerción fáctica y validez legítima, los que posibilitarían un proceso de integración social, ante el continuo disenso al interior de las sociedades modernas, o permiten aceptar a los participantes en la interacción una coacción jurídica moderada. Por tanto, asistiríamos a una cierta disolución de la paradoja ya señalada.

Habermas insiste, en este lugar, en que esta fractura entre facticidad y validez se debe a que se han desmoronado aquellas garantías meta-sociales anejas a lo sagrado. Con ello se ha disuelto aquella aleación de validez y facticidad que se producía en la dimensión de la validez misma. Habermas concluye este desarrollo presentando desde ya la solución a esta paradoja que se da en las sociedades modernas entre facticidad y validez. Se trata de la mediación social de facticidad y validez a través del derecho.

«La solución de este enigma la encontramos en ese sistema de derechos que dota a libertades subjetivas de acción de la coerción del derecho objetivo (mit dem Zwang des objektiven Rechts ausstattet). Pues desde el punto de vista histórico los derechos subjetivos privados, que definen ámbitos de libertades individuales de acción y por tanto están cortados a la medida de una persecución estratégica de intereses privados, constituyen también el núcleo del derecho moderno» ${ }^{26}$.

De este modo, el problema de la integración social o los problemas de legitimación toman, ahora, un giro jurídico-comunicativo, a partir del concepto de legalidad desarrollado por Kant, el cual parte de los derechos subjetivos para explicar el complejo modo de validez del derecho en general. Kant ve en la validez jurídica, una conexión interna, fundada en el propio derecho, entre coerción y libertad. Conexión que permite a la vez estabilizar la relación entre facticidad y validez.

«En el modo de validez del derecho la facticidad de la imposición del derecho por parte del Estado se entrelaza con la fuerza fundadora de legitimidad que caracteriza a un procedimiento de producción del derecho, que por su propia pretensión había de considerarse racional por ser garantizador de la libertad ${ }^{27}$.

Para Habermas, la paradoja que señalábamos de que para los propios sujetos agentes, facticidad y validez se separaran como dimensiones que se excluyen entre sí, «queda resuelta con el concepto kantiano de legalidad: las normas jurídicas son a la vez, aunque en aspectos distintos, leyes coercitivas y leyes de la libertad ${ }^{28}$.

24 Habermas, J., 1992, 44 [22000, 88-89].

25 Habermas, J., 1992, 44 [22000, 89].

26 Habermas, J., 1992, 45 [²2000, 89-90].

27 Habermas, J., 1992, 46 [22000, 90].

28 Habermas, J., 1992, 46 [22000, 91]; cf. KANT, I., ${ }^{2} 1994,37$ ss. 
Para Habermas, la relevancia de esta solución está en que ella también puede ser explicada desde la perspectiva de la teoría de la acción. Es decir, por un lado, los actores son libres para situarse en cualquiera de las perspectivas que ofrecen los dos componentes de la validez jurídica: coerción y libertad. Por otro, la validez del derecho positivo es tautológica, es decir, que vale como derecho lo que conforme a procedimientos jurídicamente válidos queda establecido como derecho. Por tanto, pese a la posibilidad jurídicamente dada de quedar derogado en algún momento, mantiene toda su fuerza y vigor, mientras ello no ocurra ${ }^{29}$. De este modo, el derecho positivo establecido no queda sujeto a la validez convencional de los usos y costumbres. Su apoyo y fundamento se encuentra en:

«la facticidad artificialmente producida de la amenaza que representan unas sanciones jurídicamente definidas, cuya imposición puede reclamarse a los tribunales. Por el contrario, la legitimidad de las reglas se mide por la desempeñabilidad o resolubilidad discursiva de su pretensión de validez normativa, y en última instancia a si han sido producidas en un procedimiento legislativo que quepa considerar racional, o a si por lo menos hubieran podido ser justificadas desde puntos de vistas pragmáticos, éticos y morales» ${ }^{30}$

Con esta definición comunicativa de la validez y legitimidad de la norma se quiere asegurar de que la validez jurídica de una norma pueda actuar en una doble dimensión respecto del sujeto agente. Es decir, es sujeto agente el que puede actuar en una doble perspectiva respecto de la norma. O como hecho social que restringe el espacio social del propio actor (observancia estadísticamente medida de la norma); o como - para quien actúa comunicativamente- expectativas de comportamiento dotadas de carácter obligatorio, en relación con las cuales se presupone entre los miembros de la comunidad jurídica un acuerdo racionalmente motivado, "que hace posible en todo momento una observancia de la norma por respeto a la ley (die eine Befolgung der Norm aus Achtung vor dem Gezetz jederzeit möglich macht)» ${ }^{31}$.

A partir de estas consideraciones, Habermas va a concebir la integración social como un proceso de producción de normas. De este modo, se convierte el sistema jurídico en el auténtico lugar de la integración social ${ }^{32}$. Pero se trata de un proceso de formación de derecho positivo que también ha de ser legítimo. Y ello implica que el legislador debe procurar la legitimidad de la ley garantizando iguales libertades para todos y, que la libertad del arbitrio de cada uno sea compatible con la libertad de cada uno de los demás ${ }^{33}$. Dicho proceso productivo de normas, tiene también como ingredientes esenciales a los derechos de participación y comunicación. Ahora bien, los ciudadanos implicados en este proceso de producción, no pueden concurrir a él como meros sujetos jurídicos privados aislados, que actúan orientándose por el propio éxito. Sino que para que el proceso de legitimación

29 Cf Habermas, J.,1992, 47 [22000, 91].

30 Habermas, J., 1992, 47-48 [22000, 92].

31 Habermas, J., 1992, 49 [22000, 93].

32 Es importante aquí destacar el contraste existente entre el texto de 1981 y el presente. En el primero el derecho es instrumento de colonización del mundo de la vida, en cambio, en el segundo el derecho pasa a ser el auténtico locus que posibilita la integración social.

33 Cf. Habermas, J., 1992, 50 [22000, 94]. 
sea eficaz, dichos derechos subjetivos, necesariamente, «han (müssen) de vérselos y tornárselos efectivos en la actitud de participantes en una práctica de entendimiento intersubjetivo, que actúan orientándose al entendimiento» ${ }^{34}$. Por tanto, el concepto mismo de derecho moderno, lleva en germen la idea democrática de que «la pretensión de legitimidad de un orden jurídico construido de derechos subjetivos sólo puede desempeñarse o resolverse mediante la capacidad de integración social aneja a la voluntad concordante y unida de todos (übereinstimmenden und vereinigten Willens aller) los ciudadanos libres e iguales» ${ }^{35}$. Lo que quiere destacar aquí Habermas, es la necesidad de comprender que las leyes coercitivas necesariamente tienen que (müssen) acreditar su legitimidad como leyes de la libertad en el proceso - y mediante la forma del proceso- de producción del derecho. O de otro modo, «la positividad del derecho lleva aneja la expectativa de que el procedimiento democrático de producción del derecho fundamente y funde una presunción de aceptabilidad racional de las normas estatuidas» ${ }^{36}$. Lo que aquí está en juego para Habermas es el concepto de autonomía del ciudadano, que a través de una voluntad libre y una capacidad de autolegislación racional, otorga legitimidad a los procesos de producción de normas jurídicas. Por tanto, la legitimidad del proceso sólo puede depender de un consenso básico de fondo de los ciudadanos ${ }^{37}$. Esta autonomía ciudadana y exigencia de consenso básico, implican al hecho de que el derecho positivo no puede asegurar su legitimidad sólo a través de una legalidad que deja a los destinatarios entregados a la arbitrariedad de sus intereses y motivos. Habermas intenta resolver la interrogante de, ante una autonomía tan radical del ciudadano para solidarizarse o desolidarizarse ante los procesos de producción de normas, cómo asegurar un consenso básico, que antiguamente estaba dado en la eticidad convencional apoyada por lo sacro. Pues las actuales condiciones de la sociedad moderna en su complejidad han dejado a la «acción comunicativa, suelta, deslimitada (entschränkte), liberada de sus viejos límites, suprimida en ella toda barrera, ni puede quitarse de encima el encargo que ahora recibe de asegurar y operar de la integración social, ni tampoco puede pretender desempeñarlo en serio» ${ }^{38}$. Para Habermas esta cuestión no es fácil.

«Pues sin respaldo religioso o metafísico, el derecho coercitivo, cortado a la medida de un comportamiento al que no se exige sino que se ajuste a la ley sólo puede conservar ya su fuerza de integración social haciendo que los destinatarios de esas normas jurídicas puedan a la vez entenderse en su totalidad como autores racionales de esas normas. Por este lado el derecho moderno se nutre de una solidaridad que se concentra en el papel de ciudadano y que en última instancia proviene de la acción comunicativa» ${ }^{39}$.

34 Loc. cit.

35 Habermas, J., 1992, 50 [22000, 94-95].

36 Loc. cit.

37 Cabe señalar aquí, que a medida que Habermas va precisando su concepto de integración social como proceso de producción de normas, más se adentra en una concepción del mundo moderno concebida bajo los límites de las sociedades tardo-capitalistas. Dicho límites son el Estado democrático de derecho y Estado social y democrático de derecho (cf. HABERmAS, J., 1981b, 524-547 [1998b, 505-527]).

38 Habermas, J., 1992, 56 [22000, 99]; el subrayado es nuestro.

39 Habermas, J., 1992, 51-52 [22000, 96]. 
Pero ¿cómo se articula esta doble dimensión de la acción comunicativa, que por una parte deslimita el riesgo de disentimiento discursivamente (normas y valores se tornan comunicativamente fluidos) y por otra tiene que limitarlo en función de un consenso básico de fondo de los ciudadanos que dé legitimidad a la producción de derecho positivo? Habermas intenta responder a esta cuestión señalando que «habría que inventar un sistema de reglas que asocie, a la vez que diferencie en términos de división del trabajo, ambas estrategias, a saber, la estrategia de limitar y la estrategia de deslimitar el riesgo de disentimiento que la acción comunicativa lleva en su seno» ${ }^{40}$. Habermas intenta establecer que el "permanente riesgo que representa la contradicción, que representa el decir que no, quede institucionalizado en forma de discursos y convertido en la fuerza productiva de una formación de la opinión y la voluntad políticas presuntivamente racionales» ${ }^{41}$.

Para Habermas, esta doble polaridad de la integración social a través del derecho moderno, nos pone de lleno en el problema de la positividad del derecho y su pretensión de aceptabilidad racional, o positividad y pretensión de legitimidad. Porque, por un lado, con la positividad del derecho «surge todo un fragmento de la realidad social artificialmente generada, cuya existencia es sólo discrecional, pues cada uno de sus componentes particulares puede derogarse o cambiarse ${ }^{42}$. Por tanto, la validez del derecho positivo emerge como la expresión de una pura voluntad, que presta una durabilidad discrecional a normas siempre susceptibles de ser derogadas (este voluntarismo del puro poner, enciende el phatos del positivismo jurídico). Por otro lado, el derecho positivo no puede basarse sólo en la pura voluntariedad del poner, sino también debe velar por sus condiciones de legitimidad, es decir, debe asegurarse a la vez su capacidad de integración social. Insiste aquí Habermas, en que esta conexión entre positividad del derecho y pretensión de legitimidad, «refleja ese entrelazamiento estructural de la aceptancia fundadora de hechos sociales y la aceptabilidad que las pretensiones de validez pretenden, entrelazamiento que, como tensión entre facticidad y validez, venía ya alojado en la acción comunicativa y en los órdenes sociales más o menos espontáneos o cuasinaturales» ${ }^{43}$. Se trata entonces de la tensión ideal que se da en la relación entre "coerción jurídica» (acpetancia) y la idea de autolegislación (aceptabilidad racional de las normas). Y queda también claro, que la legitimidad jurídico-social a la que aspira Habermas tiene como supuesto ideal, a la «autonomía política de los ciudadanos unidos».

\section{Debate Sobre INMigRación}

Nos queda por tratar, ahora brevemente, la cuestión del debate sobre «inmigración y el chauvinismo del bienestar» que Habermas expone en el artículo de 1990 «Ciudadanía e identidad nacional», el cual también es parte de este texto.

\footnotetext{
40 Habermas, J., 1992, 56 [22000, 99-100].

41 Habermas, J., 1992, 56 [²2000, 100].

42 Habermas, J., 1992, 57 [22000, 101].

43 Loc. cit.
} 
Habermas advierte de la difícil cuestión que es tratar el problema de la inmigración económica hacia el centro de Europa. Se trata de un problema que sólo puede tener solución mediante una política común de los Estados europeos afectados. Habermas sólo ve dos situaciones de soluciones posibles: o bien se emprenden esfuerzos importantes para que las condiciones de vida de las regiones pobres de la Europa Central y del Este mejoren enseguida, o bien Europa se verá inundada por refugiados e inmigrantes. Si embargo, la segunda alternativa presenta el inconveniente de que la disponibilidad a integrar políticamente a los inmigrantes económicos depende también de cómo perciban las poblaciones autóctonas las consecuencias sociales y económicas de la inmigración. Precisamente, aclara Habermas, que esto último es el tema del artículo ${ }^{44}$. En él se limita a abordar la correspondiente discusión moral, que gira en torno al concepto de special duties, es decir, en torno a esas obligaciones especiales que sólo se dan dentro de los límites sociales de una comunidad $^{45}$. La problemática que deben enfrentar hoy los Estados europeos respecto de la inmigración económica, es según Habermas, si puede defenderse una supremacía de los deberes especiales relacionados con la pertenencia a un Estado, frente a obligaciones universales que trascienden las fronteras de los Estados.

Habermas presenta la posición tanto de los teóricos liberales como la de los comunitaristas, haciendo algunas observaciones respecto de ambas para, posteriormente, exponer la propia. Afirma, por tanto, situarse en una situación de imparcialidad que tenga en cuenta tanto el punto de vista del habitante de una región opulenta como también el del inmigrante que busca en ella su salvación. Respecto de la posición liberal, citando a Rawls se parte del experimento mental de construir una posición original «en la que todos los que se encuentran en ella ignoran en qué sociedad van a nacer y qué posiciones van a ocupar en ella ${ }^{46}$. Desde el velo de ignorancia sugerido por Rawls no queda otra alternativa que insistir en que el derecho a emigrar quedase incluido en el sistema de las libertades básicas, al igual que el derecho de la libertad de culto, pues ambos podrían resultar esenciales para el propio plan de vida de uno. Por tanto, puntos de vistas como el de la ascendencia, leguaje, origen, etc., no debieran justificar privilegio alguno en lo concerniente a inmigración y obtención de nacionalidad.

La posición comunitarista en cambio, critica la unilateralidad de este planteamiento, debido a que pasa por alto el hecho de que los límites sociales de una comunidad política no son sólo funcionales, sino que regulan también la pertenencia a una comunidad histórica de destino y a una forma política que es constitutiva de la identidad de los ciudadanos mismos. En este respecto, cada miembro reconoce una lealtad a la comunidad, expresada en la disponibilidad a sacrificar ventajas personales para promover los interese de la comunidad ${ }^{47}$. Habermas subraya que tal concepción ya no está a la altura de las sociedades complejas, pero que, sin embargo, pone énfasis en un componente ético, que no puede pasarse sin más por alto.

44 Cf. Habermas, J., 1992, 652 [22000, 636].

45 Cf. Habermas, J., 1992, 654 [22000, 638].

46 Habermas, J., 1992, 656 [22000, 640]; cf. Rawls, J., ${ }^{2} 1995,25 s s ; 1990,33$ ss.

47 Cf. Habermas, J., 1992, 657 [22000, 641]. 
Habermas, después de tomar distancia de las propuestas comunitaristas moderadas de M. Walzer ${ }^{48}$, van Gunsteren y H. Arendt, presenta su propia opinión al respecto. Podríamos afirmar que lo que Habermas desarrolla es un cierto tipo de liberalismo moderado inspirado en el liberalismo igualitario de J. Carens ${ }^{49}$. Observemos como se articula esta propuesta:

«La exigida competencia de actuar como ciudadanos de esta particular comunidad política (this particular polity) ha de entenderse, empero, de forma muy distinta, a saber, en un sentido universalista, tan pronto como la comunidad política misma incorpora principios constitucionales universalistas. La identidad de la comunidad política, que no debe verse afectada en su integridad, tampoco por la inmigración, depende en este caso primeramente de los principios jurídicos anclados en la cultura política y no en una particular forma de vida étnico-cultural, considerada en conjunto. Y conforme a esto, de los inmigrantes debe esperarse sólo la disponibilidad a introducirse en la cultura política de su nuevo país, pero sin necesidad de tener que abandonar por ello la forma de vida cultural de la que provienen $»^{50}$.

Para Habermas y para Carens, desde el punto de vista de la sociedad receptora de inmigrantes tanto las ligaduras como los límites han de ser compatibles con principios liberales. Pues con ello, se podría acceder a una inmigración abierta que cambiaría el carácter de la comunidad receptora, pero no la dejaría sin carácter alguno $^{51}$. La conclusión que saca Habermas de esta propuesta es que los Estados europeos deberían ponerse de acuerdo en una política liberal de inmigración. Por tanto, "no deberían atrincherarse tras la barrera de un chauvinismo del bienestar contra la presión de aquellos que quieren inmigrar o que solicitan asilo» ${ }^{52}$. Habermas postula con esto, una preeminencia de la propia cultura política que constituye el contexto concreto de los derechos de ciudadanía. Sin embargo, esta preeminencia no puede constituirse como la reivindicación de una forma de vida cultural privilegiada. Pues el marco institucional del Estado de derecho democrático es lo suficientemente plástico para coexistir, en régimen de plena igualdad, múltiples formas de vida solapadas en una cultura política común.

Para Habermas lo que está en juego con la experiencia de encuentros multiculturales en países receptores de inmigrantes, son los derechos de ciudadanía y la cultura política de los países que viven bajo el régimen de Estado democrático de derecho. Y lo importante es que a este nivel, el inmigrante pueda acceder a los mismos derechos de ciudadanía que los nativos del lugar. Sin embargo, con esta propuesta habermasiana, el problema de la integración social entre diversas formas de vida (pluralidad cultural) queda impermeabilizado al acceso de una crítica racional. Es decir, que el tema de la inmigración económica hacia el centro de Europa puede ser racionalizado y solucionado a nivel de las culturas políticas que entran en competencia, porque claramente prevalece la del país receptor, pero los problemas de convivencia entre diversos modos de valorar y concebir el mundo y la

48 Cf. Walzer, M., 1993; 1996; 1998; 2001.

49 Cf. Carens, J., 1987; 1992; 1996.

50 Habermas, J., 1992, 658-659 [22000, 642].

51 Cf. Habermas, J., 1992, 659 [22000, 642].

52 Habermas, J., 1992, 659 [22000, 643]. 
vida quedan sustraídos a la reflexión racional y entregados a la simple aleatoriedad de los encuentros o desencuentros culturales entre actores que gozarían de iguales derechos de ciudadanía ${ }^{53}$.

Habermas está convencido de que su propuesta es óptima para la resolución del problema de la inmigración en la Europa Central, hasta tal punto que llega a afirmar que «sólo una ciudadanía democrática que no se cierra en términos particularistas puede, por lo demás, preparar el camino para un status de ciudadano del mundo o una cosmo-ciudadanía, que hoy comienza a cobrar ya forma en comunicaciones políticas que tienen un alcance mundial ${ }^{54}$. Desde esta perspectiva habermasiana, el problema de la inmigración queda unilateralmente tematizado, sólo como un problema de derechos ciudadanos. Sin embargo, clarifica que es un problema de justicia y una cuestión ética el otorgar igualdad de derechos a los inmigrantes, pero aún así la perspectiva sigue siendo sólo jurídica. Lo curioso del asunto es que Habermas se da cuenta de que la globalización sistémica nos ha puesto en un nuevo orden de realidad, desde el cual, lentamente, vamos avanzando hacia una sociedad mundializada, pero no puede dejar de ver esa nueva realidad sino como una mera extensión a nivel mundial del Estado democrático de derecho. Pues «el Estado cosmopolita ya ha dejado de ser un puro fantasma, aun cuando nos encontremos todavía bien lejos de él. El ser ciudadano de un Estado y el ser ciudadano del mundo constituyen un continuum cuyos perfiles comienzan ya al menos a dibujarse $»^{55}$. Por tanto, podemos anotar desde ya que hasta 1990 la respuesta de Habermas, frente al fenómeno de la integración social multicultural, consiste en un derecho liberal igualitario a una ciudadanía cosmopolita.

Otra consideración relevante de destacar es el hecho de que Habermas llega a esta propuesta a partir de un análisis de los planteamientos que comunitaristas y liberales realizan al respecto. La propuesta de Habermas es una razonable síntesis de ambas, pero con un acento o matiz más liberal, es decir, esta propuesta no es deducible del principio discursivo aplicado a la interpretación del fenómeno de la inmigración, la metodología utilizada para este análisis es la del sentido común democrático, que busca una solución de compromiso atendiendo a las mejores razones de ambos extremos. Y ello es así porque la teoría de la acción comunicativa no tiene categorías propias para tematizar el problema de la integración social multicultural, pues en la sistemática de las formas de entendimiento la categoría forma moderna de entendimiento $^{56}$ está formulada de tal modo, que excluye dicha posibilidad. Recordemos también que es esta categoría, el «punto de partida para una teoría de la moderni-

53 Augusto Hortal, comenta respecto de la propuesta sociológico-jurídica habermasina lo siguiente:

«Habermas adopta una postura distante y resignada ante la pluralidad de propuestas y tradiciones morales; reclama validez y autoridad moral, no para los contenidos, sino para los procedimientos democráticos de alcanzar el consenso. El pluralismo de convicciones y creencias constituye para él un factum ente el cual la razón nada tiene que hacer o decir, tan sólo puede admitirlo como inamovible y tratar de domesticarlo por procedimientos formales que garanticen la convivencia libre, igualitaria y justa. Esta postura da un estatuto irracional y privado a las creencias plurales; el espacio público lo ocupa la racionalidad universalista y procedimental gestionada por los funcionarios de la razón comunicativa» (HorTaL, A., 2002, "La justicia entre la ética y el derecho" en Fernández, J. y Hortal A. (comp.), 2002, 22).

54 Habermas, J., 1992, 659 [22000, 643].

55 Habermas, J., 1992, 660 [22000, 643].

56 Cf. Habermas, J., 1981b, 286; 291-293[1998b, 273; 278-280]. 
dad» y el fundamento para la crítica habermasiana sobre las patologías del mundo de la vida inducidas sistémicamente ${ }^{57}$. Podemos también subrayar que el fenómeno de la inmigración económica hacia el Centro de Europa es efectivamente una patología en el mundo de la vida de la sociedad europea, inducida sistémicamente. Pues es la globalización sistémica la que ha inducido a este nuevo y no previsto fenómeno. El punto crítico aquí vuelve a ser el hecho de que la integración social comunicativamente articulada está pensada sólo para que funcione bajo el criterio de símbolos universalmente compartidos desde los cuales es posible determinar cuál es la unidad social $^{58}$. Es decir, la integración social comunicativa sólo puede ser pensada teniendo como substrato a un solo mundo de la vida homogéneo, un solo universo simbólico compartido por todos y no desde una pluralidad de los mismos (fenómeno migratorio). Además, no se trata de cualquier mundo de la vida, la integración social comunicativa sólo es válida para un mundo de la vida postconvencional y no para mundos de la vida preconvencionales o convencionales, como es el caso del mundo de la vida de quienes inmigran. Este conjunto de observaciones críticas, nos van a permitir pasar a nuestro próximo apartado el cual consiste en una valoración y comentario crítico del texto analizado (Faktizität und Geltung).

\section{EVALUACIÓN Y COMENTARIO CONCLUSIVO}

Hasta aquí, Habermas nos ha mostrado cómo la integración social que circula por los carriles del derecho positivo moderno está problematizada por una tensión interna entre facticidad y validez. Con ello también podemos observar cómo la problemática de la integración social en Habermas sigue estando íntimamente ligada al concepto de una modernidad social tardo-capitalista, pero ahora, especificada desde el ámbito de una filosofía del derecho. El núcleo duro de la teoría de la acción comunicativa se mantiene intacto y ahora es aplicado —en su integridad - para tematizar los problemas de validez del derecho positivo moderno como agente generador de integración social. Validez que requiere de la suposición ideal de la acción de una autonomía política de los ciudadanos unidos. Es decir, se trata de un concepto de autonomía ciudadana, estrictamente moderno, que tiene como correlato al sistema jurídico que lo constituye, a saber, el Estado de derecho democrático moderno. También se trata de una asociación ciudadana, que aunque plural $^{59}$, supone a un solo mundo de la vida - constituido éste por un universo simbólico homogéneo- como su condición de posibilidad comunicativa. Por tanto, la posibilidad categorial de pensar desde este horizonte teórico habermasiano, una integración social en medio de vínculos sociales mundializados, sigue quedando cerrada. Creemos que una de las causas de ese cierre, tiene que ver con el modo en que Habermas evalúa las consecuencias y los desafíos que genera el actual proceso

57 Cf. Habermas, J., 1981b, 293 [1998b, 280].

58 Cf. GonzÁlez, A., 1994a, 51-53.

59 Cabe señalar aquí que el concepto de pluralidad democrática en el marco de un Estado democrático de derecho es algo radicalmente distinto a la pluralidad multicultural a la que hemos estado haciendo referencia. Para una mayor precisión sobre el concepto de pluralidad democrática cf. SARTORI, G., ${ }^{2} 2001,41-67$; H. Arendt, 1993, 234-250. 
de globalización sistémica. Pues aunque tiene clara conciencia de los problemas que dicha globalización lleva consigo ${ }^{60}$, Habermas — como consecuencia más inmediata de este actual estado de cosas- no puede ver más que el hecho de que en las sociedades de Occidente, articuladas en términos democráticos y de Estado de derecho, la política pierde hoy orientación, seguridad y autoconciencia ${ }^{61}$. Ante este estremecedor diagnóstico Habermas sospecha, que la raíz de este malestar e incertidumbre es que, en las sociedades occidentales articuladas en términos democráticos, «el Estado de derecho no puede tenerse ni mantenerse sin democracia radical» ${ }^{62}$. Luego, la meta de sus investigación en Faktizität und Geltung es convertir este presentimiento (Ahnung) o sospecha en una idea (Einsicht).

Sin embargo, nosotros vemos en este proceso de globalización sistémica no sólo desorientación e inseguridad, sino algo mucho más radical, a saber, un nuevo orden de realidad radicalmente inconmensurable con los órdenes sociales, económicos y políticos que la humanidad ha vivido. Pues por primera vez se nos hacen patentes los límites de la biosfera como nuestro único hogar posible y la humanidad como un todo radicalmente heterogéneo que requiere de la construcción racional de espacios de paz social, para los cuales ni la filosofía ni las ciencias sociales tienen hoy marcos conceptuales adecuados de comprensión. Precisamente este diagnóstico sobre la globalización nos lleva a diagnósticos y comprensiones diferentes de los problemas y soluciones que requieren, no ya las sociedades occidentales con Estados de derecho democráticos, sino más bien, la humanidad en su globalidad. No podemos soslayar el hecho de que ha comenzado una nueva era de la humanidad, con los actuales desarrollos de las tecnologías de la información, la cibernética y la globalización sistémica (nueva onda larga expansiva del desarrollo capitalista). Y que los ordenamientos sociales, políticos, económicos y éticos en vistas de conseguir una paz mundial, son inconmensurables con el actual marco jurídico-político-social (Estados nacionales; Estados sociales democráticos de derecho) de la sociedades capitalista del primer mundo. Ello porque es imposible pensar la paz mundial con el modelo de un gran gobierno mundial como si fuese una gran Nación de naciones, es decir, tratar simplemente de amplificar estructuras nacionales o postnacionales al ámbito de un gobierno mundial ${ }^{63}$.

60 «Ante el inmenso desafío que representa la necesidad de limitar ecológicamente el crecimiento económico y la creciente disparidad de la situación económica y social en el Norte y en el Sur; ante la tarea históricamente única de las sociedades articuladas de socialismo de Estado a mecanismos de un sistema económico diferenciado de lo político; bajo la presión de las corrientes migratorias de las regiones del Sur reducidas a la miseria, y ahora también de las del Este; en vista de los riesgos de guerras nuevamente de tipo étnico, nacional y religioso, de chantajes atómicos y de luchas internacionales por la distribución de bienes y recursos, ante este estremecedor trasfondo la política pierde hoy orientación, seguridad y autoconciencia, también en las sociedades de Occidente articuladas en términos democráticos de Estado de derecho» (HABERMAS, J., 1992, 12-13 $\left.\left[{ }^{2} 2000,60-61\right]\right)$.

61 Cf. Habermas, J., 1992, 13 [22000, 61].

62 Loc. cit.

63 Habermas está completamente en desacuerdo con esta evaluación, pues para él, el concepto de Estado postnacional que debe su realidad a los actuales procesos de globalización sistémica, debe ser continuidad de todo lo que los Estados nacionales han ganado ya en niveles de integración social y de bienestar social, pero ello con la precaución de cesar con la escisión que genera el chauvinismo del bienestar. El marco en el que Habermas expresa esta convicción, trata de la defensa 
Precisamente, porque evaluamos de un modo radicalmente distinto al de Habermas a ese estremecedor trasfondo, tenemos también derecho a presentir o sospechar que pensar una integración social multicultural pasa por una comprensión (Einsicht), no meramente pragmático-formal-lingüística de la acción comunicativa y con ello una comprensión también pragmático-formal-lingüística de la integración social que tiene como referente fáctico a una sociedad tardo-capitalista, incardinada en Estados nacionales o postnacionales (Unión Europea), sino que, más bien pasa por una comprensión (Einsicht) que sea capaz de generar un marco conceptual que nos permita entender toda la riqueza, originalidad e intrínseca normatividad de los actos y de las acciones humanas en su radical pluralidad y heterogeneidad en el contexto de interacciones sociales globales. Se trata entonces, de acceder a una radical fundamentación crítica de la acción humana, que funde desde sí misma tanto la radical heterogeneidad de los actos, acciones, actuaciones y actividades humanas, como su intrínseca unidad. Sólo a través de una empresa de este tipo podremos comenzar a caminar hacia una adecuada comprensión de las interacciones sociales en un mundo radicalmente plural, pero que a la vez es un solo mundo. Es decir, estaremos en condiciones de concebir racional y éticamente al mundo y la sociedad del tercer milenio, sociedad que presenta esa radical originalidad y novedad, que puede ser ilustrada con la imagen bíblica de la Torre de Babel. Este derecho a Babel, es radicalmente impensable desde un marco categorial de racionalidad como el presente en la teoría de la acción comunicativa de J. Habermas.

Con estas afirmaciones conclusivas, no pretendemos desconocer la relevancia que la filosofía del derecho de Habermas pueda tener para una autocomprensión más acabada de la modernidad occidental sobre sí misma; tampoco desconocemos el aporte de la peculiar definición de democracia radical que Habermas nos presenta en este texto. Pero lo que queremos clarificar, desde nuestra investigación, es la radical insuficiencia categorial de la teoría de la acción comunicativa y de la filosofía del derecho que de ella emerge para acceder a una conceptuación de vínculos sociales mundializados.

Sin embargo, no haríamos justicia a esta ingente teórica si antes no presentamos el muy relevante cambio metodológico que se ha producido en la teoría de la acción comunicativa a partir del texto Faktizität und Geltung. Se trata de la superación de la imagen del derecho como mero proceso de juridización a través del cual se produce una colonización interna del mundo de la vida ${ }^{64}$. Es decir, que en esta obra hay una visión mucho más positiva del derecho en tanto valedor del mundo de la vida frente a los imperativos sistémicos.

de la Unión Europea como la nueva y única instancia republicana a la que pueden aspirar hoy los alemanes. Por tanto, la defensa del Estado social y democrático de derecho sólo puede ser defendida en este nuevo marco referencial, puesto que los procesos de globalización sistémica, han hecho saltar por los aires, las actuales fronteras de los tradicionales Estados nacionales. En este texto la escisión del chauvinsimo del bienestar, dice relación con las resistencias a integrarse en la Unión Europea por temor a perdida de bienestar social (cf. HABERMAS, J., ${ }^{32001 b}, 181-185$ ). Habermas, no esta pensando en un radical nuevo orden de realidad mundial y multicultural, sino en salvar los niveles de integración social alcanzados en el Estado social democrático de derecho, a través de una nueva realidad postnacional: la Unión Europea.

${ }^{64}$ Cf . Habermas, J., 1981b, 522-547 [1998b, 502-526]. 


\begin{abstract}
«Dejando atrás una visión hasta cierto punto maniquea del derecho, Habermas admite, siguiendo a la sugerencia de Kaarlo Tuori (1988-54-55), que "no es posible aquella distinción entre el derecho como institución y el derecho como medio que contrapone las normas jurídicas de carácter sociointegrativo a las formas jurídicas de regulación política" [J. Habermas, 1992, 502 nota 47 (22000, 500, nota 47)], pues ha perdido la necesaria nitidez. Con el abandono de esta distinción, el derecho ha dejado de ser contemplado como una amenaza que se cierne sobre el mundo de la vida y que imponía a este dominio la asimilación de recursos y lógicas que le resultaban extraños» ${ }^{65}$.
\end{abstract}

El derecho ahora es integrado al «principio de discurso» con lo cual asume una estructura reflexiva. Con ello, abandona Habermas el concepto de juridización que concebía unilateralmente al derecho como instrumento de cosificación del mundo de la vida. Además el derecho ha adquirido un nuevo status en el interior de la teoría; ha sido elevado a la función integradora de bisagra que tiene como función «acoplar un mundo de la vida integrado normativa y simbólicamente y una esfera sistémica regida por el poder y el dinero» ${ }^{6}$.

Habermas, a través de una reformulación metodológica, ha reconceptuado el papel del derecho en medio de los componentes estructurales del mundo de la vida. Si antes el proceso de reproducción social y el de socialización estaban mediados por la dinámica comunicativa del proceso de integración social, ahora la función mediadora integradora la desempeña el derecho comunicativamente concebido. Es decir, que ahora el derecho tiene una doble funcionalidad: mediar entre mundo de la vida y sistema; y entre proceso de reproducción cultural y socialización. Pues «las acciones jurídicas constituyen el medio a través del cual se reproducen las instituciones jurídicas simultáneamente con las tradiciones jurídicas intersubjetivamente compartidas y las capacidades subjetivas de interpretación y observancia de las reglas jurídicas ${ }^{67}$.

Podemos concluir, entonces, que a nivel metodológico, Habermas ha desarrollo una muy relevante modificación de heurística positiva que le permite convertir a la teoría de la acción comunicativa en filosofía del derecho. Si antes la gran metacategoría que articulaba a la totalidad del sistema era autorreflexión emancipatoria, ella ha sido sustituida ahora por la de autolegislación emancipatoria. A partir de esta reformulación metodológica que resitúa el papel del derecho en el interior de la teoría, Habermas desarrolla su idea de democracia radical, que en lo principal consistirá en: a) poder conectar internamente los conceptos de derechos del hombre y soberanía popular (conexión interna de autonomía privada y autonomía pública), b) establecer la relación de complementación entre moral racional y derecho positivo y c) proponer una fundamentación de los derechos fundamentales en términos de teoría del discurso (principio de discurso, forma jurídica y principio democrático).

Respecto de esta propuesta habermasiana, de reformulación del sistema de los derechos desde el principio de discurso quisiéramos comentar también la interesante observación de J. C. Velasco, que advierte en el texto un cambio de polaridad, respecto del papel del derecho en el interior de la teoría. A partir del diagnóstico de la colonización interna, realizada por el sistema en el mundo de la vida a través

65 Velasco, J. C., 2000, 139.

66 Velasco, J. C., 2000, 139; cf. J. Habermas, 1992, 77-78 [²2000, 120].

67 Habermas, J., 1992, 108 [22000, 146]. 
del derecho: proceso de juridización —-tesis sustentada en el segundo volumen de Theorie des kommunikativen Handelns-, Velasco se pregunta, ¿por qué no hablar de que ahora hay en Habermas, de manera inversa, una paulatina penetración de las exigencias comunicativas en el subsistema jurídico? Se trataría, entonces, de un cierto tipo de colonización del derecho por la racionalidad dialógica comunicativa, que se verifica en la «introducción de los derechos humanos en el núcleo mismo de los ordenamientos constitucionales democráticos [y que] implica la positivación de algunos destacados requisitos práctico-comunicativos postulados por el pensamiento emancipatorio de la Ilustración ${ }^{68}$. Nuestra convicción es que la sugerencia de Velasco es razonable. Es más, es desde ella que nosotros de un modo derivado, queremos expresar nuestras aprensiones con la propuesta teórica habermasiana. Precisamente en el sentido de que advertimos también una especie de proceso de colonización inverso, pero desde el principio de discurso hacia el concepto de derechos humanos. Ya hemos reseñado la problemática teoría de la racionalidad, que supone el principio de discurso, al articularse desde la categoría forma moderna de entendimiento. Como ya hemos reseñado, se trata de una categoría postmetafísica y postconvencional, que no está abierta a la posibilidad de articularse con formas categoriales de legitimación preconvencionales y convencionales. Por tanto, a partir de esta observación, concluimos que con este texto (Faktizität und Geltung) no sólo asistimos a una reformulación del sistema de los derechos desde el principio del discurso; sino que también traspasamos a la teoría jurídica y en particular, al concepto de derechos humanos, los problemas categoriales que este principio postconvencional conlleva. Por eso es que nosotros aquí, también hablamos de una problemática colonización del concepto de derechos humanos por el principio de discurso. Es decir, que estrictamente desde los presupuestos catgoriales de la teoría de la acción comunicativa habermasiana, los derechos humanos quedarían secuestrados como patrimonio de un debate que sólo se puede realizar en el ámbito de una racionalidad postconvencional. Podemos afirmar como conclusión que este tratamiento discursivo-comunicativo de los derechos humanos va a hacer particularmente problemática — desde su fundamento catgorial— la articulación de un diálogo intercultural que tenga como base a los derechos humanos ${ }^{69}$. Precisamente porque los modos de legitimación de la integración social, en muchas de esas culturas, circulan por rieles categoriales preconvencionales y convencionales.

No podemos dejar de comentar que con la teoría de la acción comunicativa habermasiana nos enfrentamos al problema de la validez de categorías del entendimiento comunicativo, que están fácticamente enormemente cuestionadas. Es decir, Habermas ha definido en el interior del apartado «Desacoplamiento de sistema y mundo de la vida» una sistemática de las formas de entendimiento. Allí aparecen doce formas de entendimiento que articulando diferenciación de esferas de validez con ámbitos de acción que evolucionan socialmente desde formas de entendimiento primitivas preconvencionales hacia las más avanzadas postconvencionales, llegando así hasta las dos últimas categorías (11 y 12) que Habermas denomina forma moderna

68 Velasco, J. C., 2000, 141 [En este mismo número de Pensamiento se publica un artículo de Juan Carlos Velasco sobre la evaluación del concepto de Estado en Habermas.].

69 Habermas, J., ${ }^{2} 1997,110$ [1999, 99]. 
de entendimiento ${ }^{70}$ y que es el punto de partida de su teoría de la modernidad. Sin embargo, a este sistema categorial, debe hoy enfrentar una realidad completamente distinta a la del mundo moderno tardo-capitalista, que opera como referente fáctico de la teoría. La nueva realidad consiste en una globalización sistémica que ha puesto en espacios nacionales específicos a una pluralidad de mundos de la vida que van desde el preconvencional al postconvencional. Esto es lo mismo que decir, que en el cuadro de la figura 28 presentado por Habermas ${ }^{71}$ todas las categorías aparecen juntas, aunque diferenciadas en grados de evolución, y en un espacio y tiempo presente y continuo $^{72}$. Entonces, ¿no cabrá aquí una reformulación de la teoría que suponga y tematice la posibilidad de una comunicación, una interacción social y una integración social intercategorial, es decir, entre mundos de la vida con distintos grados de evolución social (tanto a nivel de complejidad sistémica como de los grados de racionalización de los mundos de la vida)? ¿Por qué Habermas teniendo tan claro el diagnóstico del nuevo orden de realidad que nos toca vivir ${ }^{73}$ no ha emprendido dicha reformulación del núcleo duro de su teoría, el cual está fácticamente cuestionado? ${ }^{74}$ Desde ya podemos adelantar que mientras dicha reformulación no ocurra, Habermas seguirá empleando un doble concepto de racionalidad para abordar teóricamente problemas sociales: cuando habla de Europa y del Estado de derecho democrático habla desde el principio del discurso, o desde presupuestos teóricos comunicativos; cuando aborda temáticas referidas a integración social intercultural lo hace desde una racionalidad del sentido común democrático (Common sense) ${ }^{75}$ al que deben subordinarse esas otras tradiciones culturales. Cómo opera este common sense en la racionalidad comunicativa será el tema de un próximo artículo.

70 Cf. Anexo n 2 de esta Investigación.

71 Cf. Habermas, J., 1981b, 286 [1998b, 272-273].

72 Aún no hemos mencionado el hecho de que a través del mercado, la cibernética y las telecomunicaciones, el mundo se hace cada vez más pequeño. Es decir, los problemas de los radicalmente otros (mundo islámico, África, Asia, América Latina están cada vez más cerca de Europa) también empiezan a ser los problemas de Europa, porque le afectan directamente.

73 Cf. Habermas, J., 1992, 12-13; 660 [22000, 60; 643].

74 «Lo que es válido ha de poder acreditarse contra las objeciones que fácticamente puedan presentarse» (HABERmas, J., 1992, 53 [22000, 97]).

75 Para comprender, por qué Habermas se desplaza hacia la consideración de una racionalidad del sentido común, queremos citar textualmente algunas consideraciones que él hace en su discurso en la entrega del Premio de la Paz otorgado por los Libreros Alemanes: «el common sense está, pues, entramado con la conciencia de persona, que pueden tomar iniciativas, cometer errores y corregirlos. Él asienta en contraposición a las ciencias una estructura de perspectiva peculiar. Como pienso- con esta conciencia de autonomía que no puede ser aprehendida de modo naturalista el common sense asegura, por otra parte, también su distancia respecto de una tradición religiosa, de cuyos contenidos normativos nosotros, no obstante, sacamos provecho/vivimos. Por cierto, el common sense democrático del ciudadano ha tomado lugar, si se quiere, en el edificio construido racional y jurídicamente que es el Estado constitucional. [...] En contraposición con la religión el common sense ilustrado democráticamente se mantiene, pues, sobre bases que no son aceptables sólo para los que pertenecen a una comunidad de fe.

[...] El common sense ilustrado democráticamente no constituye un singular, sino que describe la constitución mental de una opinión pública multivocal (vielstimmigen Öffentlichkeit)». (J. Habermas, Glauben und Wissen. Friedenspreis des Deutschen Buchhandels, Rede von Jürgen Habermas; 14 de octubre de 2001 (inédito); traducción realizada por el Prof./Dr. Cesar Lambert ). Cf. también, HABERMAS, J., 2003, 83. 


\section{Bibliografía}

Arendt, H. (1993). La Condición Humana. Barcelona: Paidós.

CANALES, I. (2004). Ética dialógica y ética praxeológica ante el problema de la integración social (tesis doctoral). Madrid: Pontificia Universidad Comillas de Madrid.

Carens, J. H. (1987). «Aliens and citizens»: the case for Open borders, en Review of Politics, vol. 49/2, 251-273.

Fernández, J. y Hortal, A. (comp.) (2002). Ética de las profesiones jurídicas. Madrid: Pontificia Universidad Comillas.

GonZÁlez, A. (1994a). Un solo Mundo: la relevancia de Zubiri para la teoría social (tesis doctoral). Madrid: Universidad Pontificia Comillas.

Habermas, J. (1981a). Theorie des kommunikativen Handelns. Band I. Handlungsrationalität und gesellschaftliche Rationalisierung. Frankfurt am Main: Suhrkamp Verlag, ${ }^{3} 1999$ (Teoría de la Acción Comunicativa: racionalidad de la acción y racionalización social. Madrid: Taurus, $1998 a$, vol. I).

- (1981b). Theorie des kommunikativen Handelns. Band II. Zur Kritik der funktionalistischen Vernunft. Frankfurt am Main: Suhrkamp Verlag, ${ }^{3} 1999$ (Teoría de la Acción Comunicativa: crítica de la razón funcionalista. Madrid: Taurus, 1998b, vol. II).

- (1983). Moralbewubtsein und Kommunikatives Handeln. Frankfur am Main: Suhrkamp Verlag, ${ }^{7} 1999$ (Conciencia moral y acción comunicativa. Barcelona: Península, 1985).

- (1984). Vorstudien und Ergänzungen zur Theorie des kommunikativen Handelns. Frankfurt am Main: Suhrkamp Verlag (Teoría de la Acción Comunicativa: complementos y estudios previos. Madrid: Catedra, colecc. Teorema, 1997).

- (1991a). Texte und Kontexte. Frankfurt am Main: Suhrkamp Verlag, ${ }^{2} 1992$ (Textos y contextos. Barcelona: Ariel, 1996).

- (1991b). Escritos sobre moralidad y eticidad. Barcelona: Paidós.

- (1992) Faktizität und Geltung. Beiträge zur Diskurstheorie des Rechts und des demokratischen Rechtsstaats. Frankfurt am Main: Suhrkamp Verlag, ${ }^{5} 1997$ (Facticidad y Validez. Sobre el derecho y el Estado democrático de derecho en términos de teoría del discurso. Madrid: Trotta, $\left.{ }^{2} 2000\right)$.

- (21997). Vom sinnlichen Eindruck zum symbolischen Ausdruck. Philosophische Essays. Frankfurt am Main: Suhrkamp Verlag (Fragmentos filosófico-teológicos. De la impresión sensible a la expresión simbólica. Madrid: Trotta, 1999).

- (1998). Die postnationale Konstellation: politische Essays. Frankfurt am Main: Suhrkamp Verlag (La constelación posnacional. Ensayos políticos. Barcelona: Paidós, 2000).

- ( $\left.{ }^{3} 2001 b\right)$. Más allá del Estado nacional. Madrid: Trotta.

- (2003) Acción comunicativa y razón sin transcendencia. Barcelona: Piadós.

SARTORI, G. (22001). La sociedad multiétnica. Pluralismo, multiculturalismo y extranjeros. Madrid: Taurus

Velasco, J. C. (2000). La teoría discursiva del derecho. Sistema jurídico y democracia en Habermas. Madrid: Centro de Estudios Políticos y Constitucionales/BOE.

Walzer, M. (1993). Las esferas de la justicia. Una defensa del pluralismo y la igualdad. México: Fondo d e Cultura Económica. 